\title{
Coping Strategies of Stress Adopted by Female Employees with Children in the University of Cape Coast: Implications for Management Practices
}

\author{
*Regina Sally Maison: Foso College of Education, Assin Foso, Ghana \\ Grace Yeboah: St. Louis College of Education, Kumasi, Ghana \\ Grace Aba Mensah: Wesley College of Education, Kumasi, Ghana \\ Mabel Anane: Foso College of Education, Assin Foso, Ghana.
}

\begin{abstract}
The study investigated the coping strategies of stress adopted by female employees with children in the university of Cape Coast. A descriptive study was the designed employed in carrying out the study. Two hundred and four (204) respondents were sampled from 431 female employees with children to answer a set of questionnaires. The results revealed that demands from husbands and thinking of promotional issues were some of the stressors that confronted the respondents. The major effects of stress among the respondents were their inability to plan well and lack of concentration on household chores. The result showed that the most prevailing coping strategy adopted by the respondents was engaging in conversation with friends and family members as well as getting assistance from colleagues. It was concluded that female employees with children in the University of Cape Coast go through stress, which emanates from different sources. Some of the recommendations were that management of the University must educate their employees on and appropriate strategies to cope with their stress. That could be done by management through seminars conferences, workshops on coping strategies of stress.
\end{abstract}

Key words: Work stress, Coping strategies, Female employees, University of cape coast.

\section{Introduction}

In today's world, stress has become a worldwide phenomenon, which occurs in various forms in every workplace. Employees are generally working for longer hours, as the rising levels of responsibilities require them to exert themselves even more strenuously to meet rising expectations about work performance.

The word 'stress' is not unfamiliar to most people. Stress is defined as the physiological and psychological reactions to certain events in the environment. Some people defined stress as events or situations that caused them to feel tension, pressure or negative emotions, such as anxiety and anger. Stress is an unpleasant state of emotional and physiological arousal that people experience in situations that they perceive as dangerous or threatening to their well- being (Tenibiaje, 2013)

Hans Selye was one of the founding fathers of stress research. His view was that "stress is not necessarily something bad - it all depends on how you take it. The stress of exhilarating, creative successful work is beneficial, while that of failure, humiliation or infection is detrimental." Selye believed that the 
biochemical effects of stress would be experienced irrespective of whether the situation was positive or negative.

Since then, a lot of research has been conducted into stress over the last few years. Some of the theories behind it are now settled and accepted; others are still being researched and debated. The causes of stress can be environmental, social, biological or psychological factors that challenge an individual to change or adapt (Bourne \& Yaroush, 2003). For instance, environmental and social factors include the environment of a workplace and relationships with others whereas biological and psychological factors encompass the nutritional status, emotional wellbeing and overall health levels of an individual (Gazzaniga, Heatherton, \& Halpern, 2010).

A widely accepted definition of stress, attributed to psychologist and Professor Richard Lazarus, is, "a condition or feeling experienced when a person perceives that demands exceed the personal and social resources the individual is able to mobilize." Thus, in the psychological point of view, stress is generally used to describe a response to demands that is greater than an individual's ability to cope, which disrupts the individual's physical or mental equilibrium and poses a threat to the individual's general well-being (Lazarus \& Folkman, 1984). They suggested that for a situation to elicit a stress response, the situation has to be appraised by the individual as stressful, that is, the demands on the individual's resources exceeds his or her ability.

The sociological theory of stress views stress as an interaction of an individual's position in the social organisation that exposes them to various stressors, which in turn give rise to stress outcomes (Pearlin, 1989). It looks into the problems rooted in social roles that often endure in an individual's relationships, experiences and wellbeing causing role strain. The theory also takes into account the convergent effects of significant life events and daily life hassles that reflect important life experiences that are sometimes stressful significant life events and daily life hassles that reflect important life experiences that are sometimes stressful. Thus, the theory proposes to examine stressful experiences as a whole, in combination of various groups of stressors in the organization of lives and structure of experience to effectively analyse and pinpoint the stressors that causes durable strains.

The transactional model of stress and coping (TMS) by Lazarus and Folkman (1984) contend that stress is subjective where individuals experience the same stressor differently. This varied reaction to the same stressful event suggests that there is a transaction between individuals and their environment and a critical factor that influences the interpretation of the stressful event is the way it is appraised (Lazarus \& Folkman, 1984).

In relating Pearlin (1989) sociological theory of stress with Lazarus and Folkman (1984) TMS, similarities between the two can be observed in terms of their fundamental concepts of stress-stressful events, coping strategies or resources and the stress outcomes. Within the TMS, stress is identified as the outcome of imbalance between demands and resources, and ranges from daily hassles to major life events (Lazarus \& Folkman, 1984). Mothers with dependent children who are also working have a variety of demands and resources, and may perceive potential imbalance differently.

The widespread entry of females into the labour force is a characteristic of the past decades. Females are increasingly entering the workforce to contribute financially to the family survival. They are not only entering the work force in greater numbers but also remaining in the work force throughout their child-bearing and child-rearing years. Even with the changing societal trends and expectations, it is still 'expected' that working females should assume the traditional role of a homemaker (Nair, 2011; Noor, 1999). The added elements of motherhood in some working females increased the possibility of acute dual-role or multiple role stress as a mother, employee and spouse or partner (Kline \& Snow, 1994; McLaughlin, Cormier, \& Cormier, 1988; Meleis \& Stevens, 1992; O'neill \& Zeichner, 1985; Snow, Swan, Raghavan, Connell, \& Klein, 2003).

Noor (1999) preliminary findings on Malaysian working women's roles and wellbeing showed that the juggle between work and family demands have contributed to the adverse psychological and emotional wellbeing for the working mothers, this includes feelings of guilt, anxiety or decreased role satisfaction at work and home. Killien and Brown (1987) summarized that when demands from work and family roles opposes each other, the mother is likely to suffer stress and negative health consequences.

Stress at work is seen as one of the major psychosocial risks of work and it is one of the problems confronting employees. It is of great concern to employees, employers and psychologists, because of its high 
growing rate in ill- health, as a result of long working hours of some employees. In reference to work-related stress, defines stress as the emotional, cognitive, behavioural and psychological reaction to aversive and anxious aspects of work, work environments and work organizations. Thus, stress in the workplace poses a major problem for both the organization and employees as it negatively affects the employees' general wellbeing and work performance, and incurs costs on the organization (Spangler, Koesten, Fox, \& Radel, 2012). Work stress can be defined as the negative effects on the worker's physical and emotional health as a result of the mismatch between the worker's capabilities, resources or needs and the requirements of the job.

Sources of work stress such as work overload, job insecurity, work interpersonal relationships, role conflict, commuting stress etc. have been identified to play a primary role in employee's health and are somewhat similar for both males and females (Day \& Livingstone, 2001). Frequent absenteeism, mood disorders, tardiness and intentions to quit are usually predictors of stressful working conditions (Sandmark \& Renstig, 2010). However, work stressors unique to working females also include sexual harassment, lower chances of career advancement and sexual inequality, and these may negatively impact females (Street, Gradus, Stafford, \& Kelly, 2007).

Work life is not independent from family life and these domains may even be in conflict. Stress may result from the combined responsibilities of work, marriage, and children. Women continue to juggle multiple roles, including those roles related to the home and family, for which the women may have sole or major responsibility. Nevertheless, work stress and child bearing remain significant concerns among female employees, affecting both individuals and organizations. For the individual workers, regardless of whether stress is perceived positively or negatively, the neuroendocrine response yields physiologic reactions that may ultimately contribute to illness.

Coping is essentially defined as the efforts used to manage the internal or external demands that are appraised as potentially harmful and stressful to the individual. Coping is a process and it progresses across several stages. Lazarus and Folkman (1984) defined the stages as primary and secondary appraisal. Primary appraisal is the initial decision used to assess whether an event is harmful and controllable, it is the evaluation stage. Secondary appraisal regards the perception of the abilities to cope with the stressful event; it is the managing stage. These cognitive appraisal processes facilitate the ability to predict the type of coping strategy that one will use; whether preventive measures are taken or regulation of emotional distress.

Consequently, coping strategies are behaviours adopted by the individual in response to reduce the adverse effects of the appraised stressor (Fleming, Baum, \& Singer, 1984; Lazarus \& Folkman, 1984). According to Lazarus and Folkman (1984) there are two categories of coping strategies-problem-focused coping and emotion- focused coping. Problem-focused coping actively confronts the problem and tackles the problem head-on. It is usually used when the individual appraises the situation as optimistic and controllable (Carver, Scheier, \& Weintraub, 1999). Emotion-focused coping features behaviour that reduces the emotional distress on the stressor, for instance, avoidance, minimization, selective attention and positive comparison. This coping strategy is most likely utilised when the individual perceives the situation as unavoidable and uncontrollable (Carver et al., 1999). Nevertheless, problem-focused and emotion focused coping are not two distinct functions but both facilitate and impede each other in the coping process and may be more beneficial than the other in different situations (Lazarus \& Folkman, 1984). To facilitate the coping process, seven categories of coping resources have been identified: health and energy, positive beliefs, problem solving skills, social skills, social support and material resources.

Indeed, in the clamour for university education and with each university determined to achieve its goal, the staff are bound to be stressed. Also the freeze on employment in the public sector comes to worsen the plight of employees in the public universities. Now few numbers of workers are made to work more in terms of load. Most of these people also have families and play the roles of parents. Being a worker comes with its own level of stress and then being a woman with children further compound this stress.

This study, hence, assessed the coping strategies of stress adopted by female employees with children in the University of Cape Coast and professed some implications for management practices.

\subsection{Research Questions}

The study answered the following research questions:

1 What are the sources of stress among female employees with children in the University of Cape Coast?

2 To what extent does stress affect female employees with children in University of Cape Coast in terms 
of managing the home and work?

3 What are the prevalent coping strategies of female employees with children in the University of Cape Coast?

\section{Methodology}

Survey research design was adopted for this study. This design according to Olayiwola (2008) is an effective way of gathering data from different sources within short time at a relatively cheaper cost. Descriptive surveys or studies also serve as direct sources of valuable knowledge concerning human behaviour.

\subsection{Population}

The population for this study comprised all the female employees with the children in the University of Cape Coast. There was a total of 431 female employees with children as at January, 2017 (IMS-UCC)

\subsection{Sample and Sampling Procedure}

From the population of the study, a sample of two hundred and four (204) female employees with children were selected for the study. This was informed by the Krejcie and Morgan (1970) table for determining sample size. Purposive sampling was adopted to in selecting the required sample from the various colleges and the central administration. This technique was used because of the expertise of the respondents on the subject under discussion.

\subsection{Instrument}

A self-designed questionnaire named Female Employees with Children Questionnaire (FECQ) was used for data collection. The questionnaire was divided into four sections A, B, C and D. Section 'A' comprised of personal information of the respondents such as age, qualification and years of experience, and number of children. Section 'B' consists of items drawn on sources of stress among female employees with children. Section ' $C$ ' consists of items drawn on the effect of stress on managing the home and on job/tasks performance. Section D consists of items drawn on the coping strategies of stress. The items were structured or closed ended. They are placed on Strongly Agreed (SA), Agreed (A) Disagreed (D) and Strongly Disagreed (SD).

\section{Results}

The results of the study are presented at this section. It covers a decision rule that guided the interpretation of the results. The results are presented using tables to cover the demographic issues as well as the various research questions.

Decision Rule: In the analysis Strongly Agreed and Agreed were taken as "Agreed" while Disagreed and Strongly Disagreed were taken as "Disagreed". A mean score of 2.50 and above was considered as agreed while a mean score of 2.49 and below was considered as disagreed. Decision was based on the weighted mean score calculated based on the four-point interval used in the study. It is calculated thus $4+3+2+1=10$ $=2.5$

\subsection{Demographic Characteristics of Respondents}

Two hundred and four (204) respondents from University of Cape Coast were involved in the study. Their demographic variables were selected in line with the topic under study. The analysis of demographic characteristics is presented in Tables 1 to 3 as follows:

Table-1. Distribution of Respondents by Age.

\begin{tabular}{lll}
\hline Age & Frequency & Percentage $(\boldsymbol{\%})$ \\
\hline $21-30$ years & 34 & 16.67 \\
$31-40$ years & 97 & 47.55 \\
41-50 years & 42 & 20.59 \\
51-60 years & 31 & 15.19 \\
Total & $\mathbf{2 0 4}$ & $\mathbf{1 0 0}$ \\
\hline
\end{tabular}


Table 1 indicated the distribution of respondents by age. It showed that 97(47.55\%) fell in the age group of 31-40 years. The data also revealed that 42 of the respondents representing $20.59 \%$ fell in the age group of 41-50 years, followed by $34(16.67 \%)$ in the age group of 21-30 years. Next were 31 (15.19\%) who fell in the age group of 51-60 years. This implied that majority of the respondents were below 40years which represents the youthful age.

Table-2. Distribution of Respondents by Years of Experience.

\begin{tabular}{lll}
\hline No of years of working experience & Frequency & Percentage (\%) \\
\hline $1-5$ & 13 & 6.37 \\
$6-10$ & 84 & 41.18 \\
$11-15$ & 27 & 13.24 \\
$16-20$ & 53 & 25.98 \\
$21-25$ & 18 & 8.82 \\
26 and above & 9 & 4.41 \\
Total & $\mathbf{2 0 4}$ & $\mathbf{1 0 0}$ \\
\hline
\end{tabular}

Table 2 revealed the analysis of the distribution of respondents by number of years of experience. The table showed that respondents who fell in the group of 6-10 years were the highest representing $41.18 \%$. This was followed by 53 respondents representing $25.98 \%$ who had between 16-20 years of experience. Next were 27(13.24\%) respondents who fell between 11-15 years of experience. Eighteen respondents representing $8.82 \%$ fell in the category of $21-25$ years while $13(6.37 \%)$ and $9(4.41 \%)$ fell in the category of 1- 5 years and 26 and above years of experience respectively. This implied that majority of the respondents of the study had much more to learn in terms of experience which could inform the way they cope with stress.

\begin{tabular}{lll} 
& Table-3. Distribution of respondents by number of children. \\
\hline Number of children & Frequency & Percentage $\mathbf{( \% )}$ \\
\hline $1-5$ & 202 & 99.02 \\
$6-10$ & 2 & 0.98 \\
Total & 204 & 100 \\
\hline
\end{tabular}

Table 3 showed the distribution of the respondents by number of children. It showed that $202(99.02 \%)$ respondents had between 1-5 children. This was followed by 2 respondents representing $0.98 \%$ who had between 6 and 10 children. This implies that majority of the respondents of this study are experienced mothers who could be faced with many responsibilities.

Research Question One: What are the sources of stress among female employees with children in the University of Cape Coast?

\begin{tabular}{|c|c|c|c|c|c|c|}
\hline \multirow[t]{2}{*}{ Agree } & \multicolumn{6}{|c|}{ Disagree Mean Score Remarks } \\
\hline & $\mathbf{F}$ & $\%$ & $\mathbf{F}$ & $\%$ & & \\
\hline Marital separation & 120 & 58.82 & 84 & 41.18 & 2.58 & Agreed \\
\hline Divorce & 113 & 55.39 & 91 & 44.61 & 3.20 & Agreed \\
\hline I think of promotional issues at the work place & 142 & 69.61 & 62 & 30.39 & 3.43 & Agreed \\
\hline Demands from husband & 143 & 70.10 & 61 & 29.90 & 3.83 & Agreed \\
\hline Demands from children & 122 & 59.80 & 82 & 40.20 & 2.72 & Agreed \\
\hline Religious activities & 117 & 57.35 & 87 & 42.65 & 2.88 & Agreed \\
\hline Low levels of income & 141 & 69.12 & 63 & 30.88 & 2.97 & Agreed \\
\hline Ill health & 105 & 51.47 & 99 & 48.53 & 2.84 & Agreed \\
\hline Attitude of colleague workers & 129 & 63.24 & 75 & 36.76 & 2.63 & Agreed \\
\hline Attitude of students & 136 & 66.67 & 68 & 33.33 & 2.85 & Agreed \\
\hline Attitude of management & 103 & 50.49 & 101 & 49.51 & 2.73 & Agreed \\
\hline Aggregate Mean score & & & & & 2.87 & Agreed \\
\hline
\end{tabular}

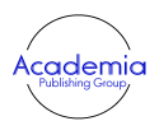

International Journal of Educational Studies

Vol. 2, No.2, pp. 100-108

2019

DOI: $10.53935 / 2641-533 x . v 2 i 2.111$

"Corresponding Author: Regina Sally Maison Funding: This study received no specific financial support.

Article History

Received. 25 April 201

Revised. 30 May 2019

Accepted: 8 July 2019

(C) 2019 by the authors; licensee Academic Publishing Group

Disagree Mean Score Remarks 
From Table 4, there was an aggregate mean score of 2.87 which indicated that all the factors in the table are sources of stress. An item by item analysis however showed that "Demands from husband" was the most dominant source of stress with a mean score of 3.83 which was even higher than the aggregated mean score. Extra four of the items were above the aggregated mean score. These were "I think of promotional issues at the work place" with a mean score of 3.43 followed by "Divorce" with a mean score of 3.20. The others were "Low levels of income" and "Religious activities" which had mean scores of 2.97 and 2.88 respectively. The item the respondents considered as the least source of stress was "Marital separation" with a mean score of 2.58 .

Research Question Two: To what extent does stress affect female employees with children in University of Cape Coast in terms of managing the home and work?

Table-5. Effects of Stress on Female Employees with Children in Terms of Managing the Home and Work Items

\begin{tabular}{llllllll} 
Agree & Disagree Mean Score Remarks \\
\hline & F & \% & F & \% & & \\
\hline I am not able to plan well. & 158 & 77.45 & 46 & 22.55 & 2.89 & Agreed \\
I lack concentration on household chores. & 127 & 62.25 & 77 & 37.75 & 2.92 & Agreed \\
I have a poor interpersonal relationship with my spouse. & 161 & 78.92 & 43 & 21.08 & 2.69 & Agreed \\
I am not sexually active & 123 & 55.17 & 96 & 43.05 & 2.73 & Agreed \\
I always feel tired and ill & 148 & 21.52 & 22 & 9.87 & 2.82 & Agreed \\
I am not able to achieve goals and projects set. & 156 & 25.11 & 39 & 17.49 & 2.71 & Agreed \\
I have poor interpersonal relationship with my children & 138 & 17.04 & 27 & 12.11 & 2.59 & Agreed \\
Poor attitude/zeal to work & 137 & 16.59 & 31 & 13.90 & 2.79 & Agreed \\
I perform poorly on the job. & 120 & 44.84 & 56 & 25.11 & 2.68 & Agreed \\
Longer time in tasks accomplishment. & 164 & 28.70 & 57 & 25.56 & 2.63 & Agreed \\
I am not able to learn or study effectively. & 190 & 40.36 & 69 & 30.94 & 2.66 & Agreed \\
Aggregate Mean Score & & & & & 2.76 & Agreed \\
\hline
\end{tabular}

From Table 5, the aggregate mean score of 2.76 agreed that stress has negative effect on female employees with children in public universities in terms of managing their home and work. The respondents agreed to all the items as effects they go through in one way or the other. What affected the respondents most was the item "I lack concentration on household chores" With the mean score of 2.92 followed by "I am not able to plan well" with a mean score of 2.89. The respondents also agreed that stress makes them feel tired and ill with a mean score of 2.82. Also $156(25.11 \%)$ indicated they were not able to achieved set goals. In terms of time taken for job completion, the respondents agreed that stressed female workers take longer time to perform a given tasks. This was seen in the mean score of 2.63 and percentage (28.70\%) agreement. Research Question Three:

What are the prevalent coping strategies of female employees with children in the University of Cape Coast?

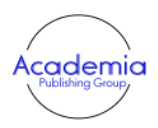

International Journal of Educational

Studie

Vol. 2, No.2, pp. 100-108

2019

DOI: $10.53935 / 2641-533 x . v 2 i 2.111$

Corresponding Author: Regina Sally Maison Funding: This study received no specific financial support.

Article History:

Received: 25 April 2019

Revised: 30 May 2019

Accepted: 8 July 2019

Published: 28 August 2019

(C) 2019 by the authors; licensee Academic Publishing Group
Table-6. Coping Strategies of Female Employees with Children in the University of Cape Coast.

\begin{tabular}{lll}
\hline Items & Frequency (N) & Percentage (\%) \\
\hline $\begin{array}{l}\text { I use labour saving devices } \\
\text { machines). }\end{array}$ & 169 & 82.84 \\
I resort to eating balance diet & 131 & 64.22 \\
I engage in regular exercise & 98 & 48.04 \\
I take in deep breathing & 152 & 74.51 \\
I listen to soft music & 191 & 93.63 \\
I relief myself with drugs & 127 & 62.25 \\
I take a good rest & 123 & 60.29 \\
I talk to a counsellor & 84 & 41.18 \\
I engage in a chat with friends \&Colleagues & 197 & 96.57 \\
\hline
\end{tabular}

It is evident that the most prevailing coping strategy adopted by the respondents was "I engage in a chat with friends and Colleague" 197(96.57\%). This was followed by "I listen to soft music" 191(93.63\%). The 
next was "I use labour saving devices or equipment (eg. washing machines)" 169(82.84\%). The least coping strategy adopted was "I talk to a counselor" $84(41.18 \%)$.

\section{Discussion}

The result obtained in respect of research question one revealed that the respondents agreed to all the items. This finding is supported by Maisamari (2000) who observed that women perform multiple roles which make them vulnerable to stress. He added that women with children are stressed by almost all their daily activities. It was also revealed from the study that the most dominant source of stress was "demands from husband". After going through a hard day's job, the female is expected to come home to cook for the family, take care of the children and also meet the sexual needs of the husband. It was therefore not surprising that the respondents indicated that what stresses them most was demands from their husbands. This finding is buttressed by the finding of Saeed (2015) when he found among females with children in Alexandra, Egypt that their number one stressor was demands from their husbands. According to him, $86 \%$ out of the 350 respondents took that position.

The second research question revealed that stress has negative effect on female employees with children in the University of Cape Coast in terms of managing their home and work. This finding is consistent with the finding of Stephens (2014) who found among nursing mothers in Newzeland that stress was detrimental to their health and to their work life as well. The finding also conformed with Noor (1999) preliminary findings on Malaysian working women's roles and wellbeing showed that the juggles between work and family demands have contributed to the adverse psychological and emotional wellbeing for the working mothers; this includes feelings of guilt, anxiety or decreased role satisfaction at work and home. Out of the 275 respondents, $91 \%$ of the respondents responded in the affirmative with regards to this finding.

The finding of the study is however contrary to the finding of Rogers who found in Maryland that stress had a positive effect on high school students. It was evident from his study that stress served as a catalyst for $87 \%$ of the students. They indicated that stress got them to perform effectively on a task. Seventy seven percent of respondents revealed that stress got them to learn for examinations.

One of the findings from the current study about what affected the respondents most was the item "I lack concentration on household chores". Another finding was that the respondents could not plan effectively as a result of stress. These findings were also revealed in the finding of Asare and Ntim (2013). They found that stress affects the thinking patterns of people and gets manifested in the way they plan for a task, execute and concentrate on its smooth running to a successful end. To a larger extent success is dependent on effective planning. Lack of it pervades failure in all facets of life.

In studies of Nurudeen (2012); Nelson (2015) and Asafuah (2016) they all found that one of the ways people cope with stress was to engage in a conversation with people. In Asafuah's study, 74\% out of 185 respondents affirmed that talking to their roommates was the surest way they dealt with their stress. Asafuah added that the respondents indicated that this coping strategy was problematic as their roommates could share the concerns and challenges with other people. They however adopted that coping strategy because of the professional counsellors were not readily available to talk to.

Nelson (2015) on his part found among female civil servants in Malaysia that chatting with a friend or a family member was one of the ways they coped with their stress. Out of 310 respondents', $88 \%$ agreed that talking to someone was a coping strategy of stress they had adopted over the last three years. On a similar account, Nurudeen (2012) found in Pakistan that student nurses adopted talking to their friends as the coping strategies of stress. He indicated that there is a statistically significant difference between first and final year students with regards to coping strategies of stress adopted. While the first year students resorted to talking to friends, the final year students' chose parties as their number one strategy of managing stress.

\section{Conclusion}

Based on the findings of the study, it is concluded that the issue of workplace stress can no longer be ignored. Female employees with children in the University of Cape Coast go through stress, which emanates from different sources. This stress has negative effect on them, their home as well as their work. These effects may not only affect their persons but also the people around them such as the colleagues at the work place, their husbands and their children. This may eventually have a concomitant effect on institutional and national productivity and growth. It also came to light that female employees with children have a number of 


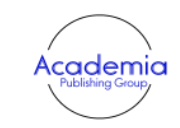

International Journal of Educational

Studie

Vol. 2, No.2, pp. 100-108

2019

DOI: $10.53935 / 2641-533 x . v 2 i 2.111$

Corresponding Author: Regina Sally Maison Funding: This study received no specific financial support.

Article History

Received: 25 April 2019

Revised: 30 May 2019

Accepted: 8 July 2019

Published: 28 August 2019

(C) 2019 by the authors; licensee Academic Publishing Group strategies they adopt in coping with their stress. Some of these strategies may be inimical to their own success as well as that of family and the work place.

\subsection{Implications for Employees and Management}

Even though the study was on coping strategies of female employees with children in the University of Cape Coast, it is an undeniable fact that all employees experience stress in one way or the other. Stress is a major $20^{\text {th }}$ century ailment producing an increase in blood sugar level, adrenalin, heart rate, cholesterol level and blood pressure (Morgan \& Baker, 1985). Heart attacks and strokes now kill more people than all other diseases combined (Scott \& Spooner, 1989). Management of work-related stress is therefore the sole responsibility of the employers and employees.

\subsection{Implications for Employees}

Employees need to become aware of themselves and of how the stress in their lives is impacting negatively on them, their colleagues and their families and should be able develop meaningful relationships with individuals in a peer group, the family or colleagues who are likely to understand their feelings and reactions to stress.

Employees would be well advised to:

- Differentiate between stressors which are avoidable and those which are beyond control

- Recognize the real causes of their stress

- Be assertive in expressing their desires and opinions

- Have confidence in their ability to work through stressful situation

- Practice an activity which helps to reduce the psychological and physiological consequences of stress

\subsection{Implications for Management}

Organizations have an essential role to play in minimising the stress levels of their employees. As Glowinkowski and Cooper (1986) observe, it is only when organisations accept their responsibility to help employees manage their stress that we will begin to deal effectively with employee's stress.

1. With an increasing number of female professionals entering workplace, there is the need for management to identify factors that are stressful to women that appropriate measures are put in place to help them to manage their stress. They should recognize the importance of developing corporate policies that minimize the stresses and strains which are particularly pertinent to working women and take cognizance of the fact that men and women at different job levels experience special concerns and vulnerabilities

2. Management should acknowledge the reality of dual-career couples and families and accommodate them by introducing affirmative action activities in the form of career planning and counseling and support network for women. These changes would help reduce anxiety and sex-role conflicts among working women, thus allowing organizations to use a major segment of the workforce more efficiently.

3. Management should ensure that every worker is aware of the stressors that are related to work. Promotion of wellbeing at work should be effected through the development of varieties of initiatives designed to raise awareness of stress and combat stress. This could be through seminar, courses, and leaflets. These activities will empower staff to recognize and manage stressful situations more effectively.

4. The University, through the Directorate of Human Resource should have a policy document on Occupational Health and Wellbeing. The document should be able to address the following issues:

a. The difference between pressure and stress?

b. Sources of pressure and signs of stress

c. The Employees' role in preventing stress and managing pressure

d. The Managers' role in preventing stress and managing pressure

5. Management should ensure that every worker, especially, staff at the Central Administration is encouraged to go on leave annually. This will help reduce stressful feelings and emotions by allowing them to take time off their busy schedules. 
6. Management should engage the services of professional counsellors to offer guidance services to employees in order to reduce their risks to stress and incapacitating consequences.

\section{References}

Asafuah, S. (2016). Stress among female students of Catholic University College. South African Journal of Psychology, 35(2), 209 224.

Asare, K., \& Ntim, S. (2013). Stress among unemployed youth in Ghana. International Journal of Social Sciences, 2(4), 13 - 25.

Bourne, L. E. J., \& Yaroush, R. A. (2003). Stress and cognition: A cognitive psychological perspective. Boulder, Colorado: University of Colorado.

Carver, C., Scheier, M. F., \& Weintraub, J. K. (1999). Assessing coping strategies: A theoretically based approach. Journal of Personality and Social Psychology, 56(2), 267-283.

Day, A. L., \& Livingstone, H. A. (2001). Chronic and acute stressors among military personnel: Do coping styles buffer their negative impact on health? Journal of Occupational Health Psychology, 6(4), 348-360.

Fleming, R., Baum, A., \& Singer, J. E. (1984). Toward an integrative approach to the study of stress. Journal of Personality and Social Psychology, 46(4), 939-949.

Gazzaniga, M. S., Heatherton, T. F., \& Halpern, D. F. (2010). Psychological science (3rd ed.). New York: W. W. Norton \& Company.

Glowinkowski, S. P., \& Cooper, C. L. (1986). Managers and professionals in business/industrial settings: The research evidence. Journal of Organizational Behavior Management, 8(2), 177-194.

Killien, M., \& Brown, M. A. (1987). Work and family roles of women: Sources of stress and coping strategies. Health Care for Women International, 8(2-3), 169-184.

Kline, M., \& Snow, D. (1994). Effects of a worksite coping skills intervention on the stress, social support, and health outcomes of working mothers. Journal of Primary Prevention, 15(2), 105-121.

Krejcie, R. V., \& Morgan, D. W. (1970). Determining sample size for research activities. Educational and Psychological Measurement, 30(3), 607-610.

Lazarus, R. S., \& Folkman, S. (1984). Stress, appraisal and coping. New York: Springer.

Maisamari, J. A. (2000). The effect of stress on career women. Psychological Review, 66(3), 183-201.

McLaughlin, M., Cormier, L. S., \& Cormier, W. H. (1988). Relation between coping strategies and distress, stress, and marital adjustment of multiple-role women. Journal of Counseling Psychology, 35(2), 187-193.

Meleis, A. I., \& Stevens, P. E. (1992). Women in clerical jobs: Spousal role satisfaction, stress, and coping. Women \& Health, 18(1), 23-40.

Morgan, P., \& Baker, H. (1985). Building a professional image: Dealing with job stress. Supervisory Management, 30, 23-28.

Nair, E. (2011). Urban career women and stress in Southeast Asia. Journal of Adult Development, 18(2), 62-65.

Nelson, F. (2015). Stress among female civil servants in Malaysia. Journal of Applied Psychology, 71, 630 - 640

Noor, N. M. (1999). Roles and women's well-being: Some preliminary findings from Malaysia. Sex Roles, 41(3), 123-145.

Nurudeen, A. (2012). Workplace stress among newly employed graduates in Pakistan. International Journal of Management and Social Sciences, 3(5), $45-59$.

O'neill, C. P., \& Zeichner, A. (1985). Working women: A study of relationships between stress, coping and health. Journal of Psychosomatic Obstetrics \& Gynecology, 4(2), 105-116.

Olayiwola, S. (2008). Dimensions of job stress among public secondary principals in Oyo State. Nigeria: Ile-Ife.

Pearlin, L. I. (1989). The sociological study of stress. Journal of Health and Social Behavior, 30(3), 241-256.

Saeed, A. (2015). The untold stress of submissive women; A snapshot of traditional married women of Alexandra, Egypt. Research in Personality, 13(4), 365-385.

Sandmark, H., \& Renstig, M. (2010). Understanding long-term sick leave in female white-collar workers with burnout and stressrelated diagnoses: A qualitative study. BMC Public Health, 10(1), 1-12.

Scott, N. A., \& Spooner, S. (1989). Women administrators: Stressors and strategies. Initiatives, 52(2), 31-36.

Snow, D. L., Swan, S. C., Raghavan, C., Connell, C. M., \& Klein, I. (2003). The relationship of work stressors, coping and social support to psychological symptoms among female secretarial employees. Work \& Stress, 17(3), 241-263.

Spangler, N. W., Koesten, J., Fox, M. H., \& Radel, J. (2012). Employer perceptions of stress and resilience intervention. Journal of Occupational and Environmental Medicine, 54(11), 1421-1429.

Stephens, P. (2014). Stress and health; The case of nursing mothers in Newzeland. Australian Journal of Advanced Nursing, 20(1), 3438.

Street, A. E., Gradus, J. L., Stafford, J., \& Kelly, K. (2007). Gender differences in experiences of sexual harassment: data from a maledominated environment. Journal of Consulting and Clinical Psychology, 75(3), 464-474.

Tenibiaje, D. J. (2013). Work related stress. European Journal of Business and Social Sciences, 1(10), 73-80.

\footnotetext{
International Journal of Educational

Studies

Vol. 2, No.2, pp. 100-108

2019

DOI: $10.53935 / 2641-533 x . v 2 i 2.11$

Corresponding Author: Regina Sally Maison

Funding: This study received no specific

financial support.

Article History:

Received: 25 April 2019

Revised: 30 May 2019

Accepted: 8 July 2019

Published: 28 August 2019

(C) 2019 by the authors; licensee Academic

Publishing Group
} 